\title{
Vibrational spectroscopy of trans and cis deuterated formic acid (HCOOD): Anharmonic calculations and experiments in argon and neon matrices
}

\author{
K. Marushkevich ${ }^{\text {a }}$, L. Khriachtchev ${ }^{a}$, J. Lundell ${ }^{b}$, A.V. Domanskaya ${ }^{\mathrm{a}, *}$, M. Räsänen ${ }^{\mathrm{a}}$ \\ a Laboratory of Physical Chemistry, University of Helsinki, P.O. Box 55, FIN-00014 Helsinki, Finland \\ ${ }^{\mathrm{b}}$ Department of Chemistry, University of Jyväskylä, P.O. Box 35, FIN-40014 Jyväskylä, Finland
}

\section{A R T I C L E I N F O}

Article history:

Received 30 October 2009

Available online 4 December 2009

\section{Keywords:}

HCOOD

Vibrational spectrum

$\mathrm{Ab}$ initio

Matrix isolation

cis

Conformer

\begin{abstract}
A B S T R A C T
The absorption spectra of trans and cis conformers of deuterated formic acid (HCOOD) isolated in argon and neon matrices are analyzed in the mid-infrared and near-infrared spectral regions $\left(7900-450 \mathrm{~cm}^{-1}\right)$. Vibrational excitation by narrow-band IR radiation is used to convert the lower-energy trans conformer to the higher-energy cis form. A large number of overtone and combination bands are identified. The results of anharmonic vibrational calculations (CC-VSCF) for both conformers are reported and compared to the experimental spectra.
\end{abstract}

(c) 2009 Elsevier Inc. All rights reserved.

\section{Introduction}

Formic acid exists in two planar forms differing by the $\mathrm{O}-\mathrm{H}$ bond orientation with respect to the $\mathrm{C}-\mathrm{O}$ bond with the $0^{\circ}$ and $180^{\circ} \mathrm{H}-\mathrm{C}-\mathrm{O}-\mathrm{H}$ dihedral angles (see Fig. 1). First unequivocal identification of the gas-phase absorption of the higher-energy cis form was made by analysis of rotational spectra which demonstrated that the trans conformer is lower in energy by $\sim 1365 \mathrm{~cm}^{-1}$ compared to the cis form [1]. The vibrational spectrum in the midIR region of cis- $\mathrm{HCOOH}$ was first obtained by Pettersson et al. in an argon matrix [2] and the detailed vibrational data on both forms of $\mathrm{HCOOH}$ in solid argon were reported later [3]. The preparation of cis- $\mathrm{HCOOH}$ was achieved by selective vibrational excitation which has been proved to be a powerful tool for promotion and investigation of conformational changes in cryogenic matrices [4].

The IR spectrum of trans-HCOOH is well known in matrices and in the gas phase. High-resolution measurements of all fundamental, many overtones and combination bands are available (see Ref. [5] and references therein) and an accurate assignment of the rotation-vibration spectral structure has been made with Fermi resonance taken into account [6]. Most of the fundamental bands of trans-HCOOD molecule were also recorded and analyzed in the gas phase [7] and in the matrices although the data for the overtone and combination transitions is sparse. The vibrational spec-

\footnotetext{
* Corresponding author. Fax: +358 919150279.

E-mail address: domav@yandex.ru (A.V. Domanskaya).
}

trum of trans-HCOOD measured in solid neon is close to that in the gas phase $[8,9]$. To the best of our knowledge, only one vibrational band of cis-HCOOH [COH torsion, 493.4205092(73) $\mathrm{cm}^{-1}$ ] was measured in the gas phase [10]. Since the cis conformer is about 800 times less abundant at room temperature, the use of a multi-pass cell with total path length of $38.2 \mathrm{~m}$ was necessary to accumulate reliable absorption level [10].

The vibrational spectrum of cis-HCOOD is not studies in detail. The geometry and rotational constants of the ground state have been reported from the microwave studies in the gas phase for $\mathrm{H}^{12} \mathrm{COOD}$ and $\mathrm{H}^{13} \mathrm{COOD}[11,12]$. The fundamental transitions for both conformers of HCOOD in different matrices are tabulated in Ref. [13], and a few combinations and overtones are assigned in Ref. [3]. The cis-HCOOH force field [14] might provide information about the transitions in cis-HCOOD because the potential energy function and the configuration of a molecule are practically unchanged upon isotopic substitution [15]. However, the work by Demaison et al. is mostly focused on trans- $\mathrm{HCOOH}$ and does not contain the force field for cis-HCOOH. It reports only the equilibrium geometry and rotational constants of the ground state of the cis conformer.

The present work supplies more information about cis and transHCOOD vibrational transitions, which complements the earlier studies $[3,8,9,13]$. The IR absorption spectra of cis and trans-HCOOD are measured in argon and neon matrices at $4.2 \mathrm{~K}$. The anharmonic vibrational frequencies for the trans and cis conformers, derived from the correlation-corrected vibrational self-consistent-field calculations (CC-VSCF), are used for vibrational assignment of the overtone and combination bands. 


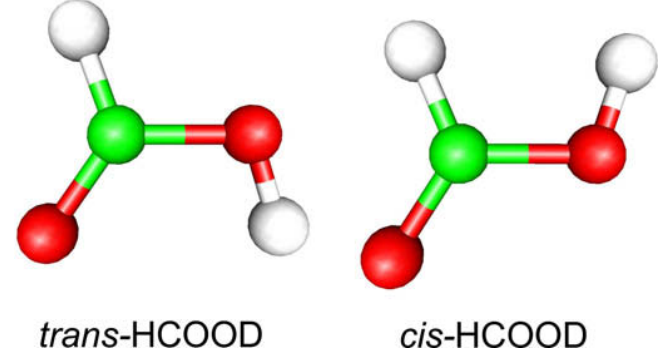

Fig. 1. trans and cis forms of formic acid. The notations follow Refs. [1-3].

\section{Experimental}

The gaseous samples were prepared by mixing deuterated formic acid HCOOD (IT Isotop, 95-98\%), with argon or neon (AGA, 99.9999\%), typically in 1:700 (Ar) and 1:1000 (Ne) proportions in a glass bulb. The matrices were deposited onto a CsI substrate at $18 \mathrm{~K}$ for $\mathrm{Ar}$ and at $4.2 \mathrm{~K}$ for Ne matrices in a closed cycle helium cryostat (Sumitomo Heavy Industries). The IR absorption spectra (7900-450 $\mathrm{cm}^{-1}$ ) were measured with a Nicolet SX-60 FTIR spectrometer at $4.2 \mathrm{~K}$. The spectral measurements in mid-IR region were carried out with the resolution of $0.25 \mathrm{~cm}^{-1}$ using a cooled MCT detector and $\mathrm{KBr}$ beamsplitter, and the near-IR spectra were recorded using a cooled $\mathrm{InSb}$ detector and quartz beamsplitter with spectral resolution of $0.5 \mathrm{~cm}^{-1}$. Typically 500 interferrograms were co-added.

trans-HCOOD was converted to the cis form by optical excitation of the first OD stretching overtone at $5174.5 \mathrm{~cm}^{-1}$ in a neon matrix and at $5149.7 \mathrm{~cm}^{-1}$ in an argon matrix with pulse energy density of $\sim 1 \mathrm{~mJ} / \mathrm{cm}^{2}$. For argon matrices, excitation at $4382.0 \mathrm{~cm}^{-1}(v \mathrm{OD}+$ $v \mathrm{C}=\mathrm{O}$ combination) was also used. An optical parametric oscillator (OPO Sunlite with IR extension, Continuum) was used as a source of pulsed IR radiation. A Burleigh WA-4500 wavemeter measured the OPO signal wavelength providing an absolute accuracy better than $1 \mathrm{~cm}^{-1}$ in the IR region.

\section{Computational method}

The computational method was essentially the same as described in our previous work [3]. The equilibrium structures of trans- and cis-HCOOD were calculated using the second-order Møller-Plesset perturbation (MP2) theory with the $6-311++G(2 d, 2$ p) basis set. This basis set reproduces the experimental structural and vibrational properties of trans formic acid with an acceptable accuracy $[16,17]$. The anharmonic vibrational properties of trans- and cis-HCOOD were studied by combining the electronic ab initio code GAMESS [18] with the vibrational self-consistent field (VSCF) method and its extension by corrections via second-order perturbation theory [19-23].

\section{Assignment and discussion}

In this section, we analyze the mid- and near-IR (450$7900 \mathrm{~cm}^{-1}$ ) spectra of the trans and cis conformers of deuterated formic acid in argon and neon matrices and compare them with the computational and, when possible, with gas-phase spectra. The bands of trans-HCOOD dominate in the spectrum after deposition. An efficient trans to cis conversion (>90\%) was achieved by excitation of the OD stretching overtone or the $v \mathrm{OD}+v \mathrm{C}=\mathrm{O}$ combination (see Fig. 2). cis-HCOOD has a larger lifetime compared to cis- $\mathrm{HCOOH}$ because the tunneling to the trans form is slowed down by deuteration [13,24,25], and their increased stability allows accurate data collection of cis-HCOOD.
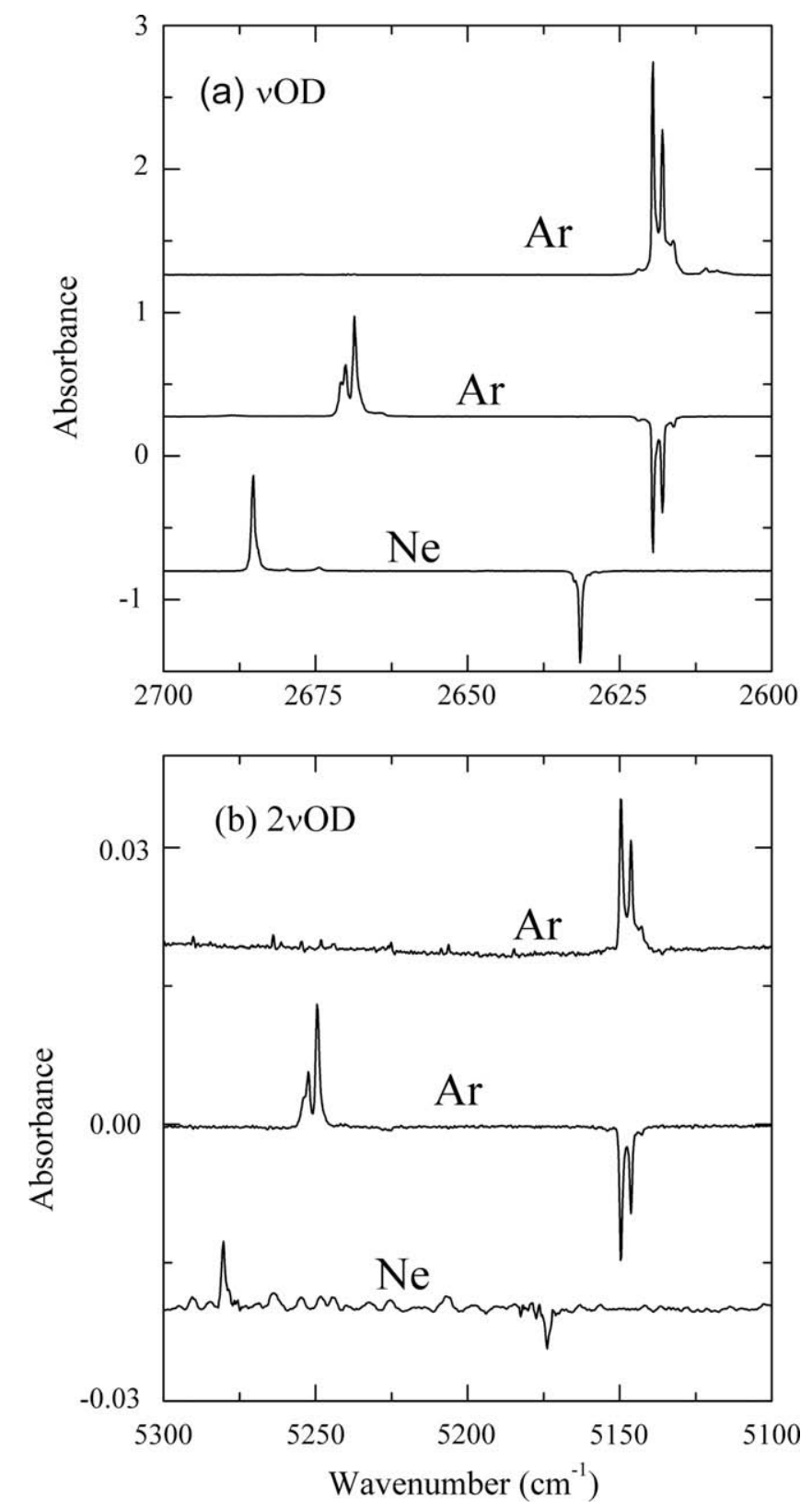

Fig. 2. (a) The OD stretching bands and (b) the OD stretching overtones of HCOOD in $\mathrm{Ar}$ and Ne matrices at $4.2 \mathrm{~K}$. The as-deposited matrices mainly contain the trans conformer as shown for an argon matrix (upper traces). Vibrational excitation converts trans-HCOOD to cis-HCOOD as presented by the difference spectra (middle and lower traces).

In a neon matrix, the bands are mostly single absorption peaks, and their frequencies are close to the gas-phase values [8]. In an argon matrix, the band splitting due to two matrix trapping sites is observed similarly to $\mathrm{HCOOH}$ [3]. Table 1 presents the observed absorption bands for the trans and cis conformers of HCOOD in argon and neon matrices and the anharmonic computational frequencies together with the available gas-phase data.

\subsection{Fundamental transitions}

The literature data $[7,8,13,26,27]$ allows a straightforward assignment of the fundamental bands of trans-HCOOD. The fundamental transitions of the cis form are relatively easy to assign as well (see Ref. [13]). In Fig. 2(a), the HCOOD spectra in the OD 
Table 1

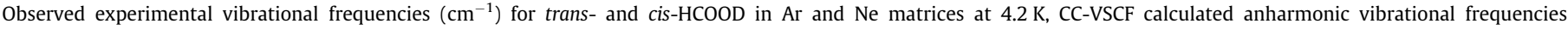
(intensities in parentheses in $\mathrm{km} / \mathrm{mol}$ ) and gas-phase data.

\begin{tabular}{|c|c|c|c|c|c|c|c|}
\hline \multirow[t]{2}{*}{ Assignment } & \multicolumn{4}{|l|}{ trans-HCOOD } & \multicolumn{3}{|l|}{ cis-HCOOD } \\
\hline & Calculated & $\mathrm{Gas}^{\mathrm{a}}$ & $\mathrm{Ar}$ & $\mathrm{Ne}$ & Calculated & $\mathrm{Ar}$ & $\mathrm{Ne}$ \\
\hline$\tau \mathrm{COD}$ & $497.5(103.1)$ & 507.5 & $\begin{array}{l}505.2 \mathrm{~s} \\
506.7 \mathrm{~s}\end{array}$ & $506.9 \mathrm{~s}$ & $361.4(29.3)$ & - & - \\
\hline OCO-CODdef. & $555.7(52.2)$ & 560.2 & $\begin{array}{l}558.7 \mathrm{~m} \\
559.7 \mathrm{~s}\end{array}$ & $557.9 \mathrm{~m}$ & $621.5(17.9)$ & $\begin{array}{l}633.0 \mathrm{~m} \\
633.6 \mathrm{~m}\end{array}$ & $629.4 \mathrm{~m}$ \\
\hline$\delta \mathrm{COD}$ & $972.7(86.2)$ & 972.8 & $\begin{array}{l}970.0 \mathrm{~m} \\
970.6 \mathrm{~s}\end{array}$ & $971.1 \mathrm{~s}$ & $897.9(7.0)$ & $\begin{array}{l}910.5 \mathrm{~m} \\
911.2 \mathrm{w}\end{array}$ & $906.8 \mathrm{~m}$ \\
\hline $2 \tau \mathrm{COD}$ & $960.9(4.2)$ & 1011.7 & $\begin{array}{l}1008.3 \mathrm{~m} \\
1009.4 \mathrm{~m}\end{array}$ & $1009.5 \mathrm{~m}$ & $688.3(0.16)$ & $740.4 \mathrm{vw}$ & $746.2 \mathrm{vw}$ \\
\hline$\omega \mathrm{CH}$ & $1033.2(0.1)$ & - & $\begin{array}{l}1035.1 \mathrm{vw} \\
1036.4 \mathrm{vw}\end{array}$ & $1037.3 v w$ & $1014.4(1.0)$ & $1041.2 \mathrm{vw}$ & $1039.3 \mathrm{vw}$ \\
\hline$v \mathrm{C}-\mathrm{O}$ & $1163.7(206.1)$ & 1177.1 & $1181.7 v s$ & 1176.9vs & $1140.9(348.2)$ & $1164.0 v s$ & $1159.0 v s$ \\
\hline$\gamma \mathrm{CH}$ & $1381.1(7.2)$ & 1368 & $\begin{array}{l}1371.1 \mathrm{vw} \\
1374.3 \mathrm{vw}\end{array}$ & $1367.9 w$ & $1403.6(2.7)$ & $\begin{array}{l}1391.0 \mathrm{vw} \\
1395.4 \mathrm{vw}\end{array}$ & $1388.0 \mathrm{vw}$ \\
\hline$\tau \mathrm{COD}+\delta \mathrm{COD}$ & $1441.0(0.0)$ & - & $1427.5 \mathrm{vw}$ & $1433.0 \mathrm{vw}$ & $1207.8(0.0)$ & - & - \\
\hline $\mathrm{OCO}-\mathrm{CODdef}+\delta \mathrm{COD}$ & $1533.5(0.1)$ & - & - & 1526.3vw & $1524.9(0.1)$ & $1543.2 \mathrm{vw}$ & $1534.2 \mathrm{vw}$ \\
\hline $\mathrm{OCO}-\mathrm{CODdef}+v \mathrm{C}-\mathrm{O}$ & $1715.6(3.7)$ & 1732.1 & $1735.7 w$ & $1730.0 \mathrm{w}$ & $1760.7(0.8)$ & - & - \\
\hline$v \mathrm{C}=\mathrm{O}$ & $1751.3(460.8)$ & 1773.6 & $\begin{array}{l}1765.6 \mathrm{vs} \\
1767.2 \mathrm{vs}\end{array}$ & $1771.0 \mathrm{vs}$ & $1789.5(434.2)$ & $\begin{array}{l}1788.9 \mathrm{~m}^{\mathrm{b}} \\
1799.3 \mathrm{vs}^{\mathrm{b}} \\
1821.0 \mathrm{~m}^{\mathrm{b}}\end{array}$ & $\begin{array}{l}1781.2 w^{b} \\
1798.9 v s^{b} \\
1818.2 v s^{b}\end{array}$ \\
\hline $2 \delta \mathrm{COD}$ & $1938.0(0.3)$ & & $1949.7 \mathrm{vw}$ & $1950.6 v w$ & $1779.9(0.1)$ & - & - \\
\hline$\omega \mathrm{CH}+\delta \mathrm{COD}$ & $2004.8(0.0)$ & - & $2008.4 v w$ & 2008.6vw & $1912.3(0.0)$ & - & - \\
\hline$v \mathrm{C}-\mathrm{O}+\delta \mathrm{COD}$ & $2129.6(3.7)$ & - & $\begin{array}{l}2144.1 w \\
2181.0 w\end{array}$ & $\begin{array}{l}2139.8 w \\
2176.8 w\end{array}$ & $2030.1(2.1)$ & $2065.1 w$ & 2055.2w \\
\hline$v \mathrm{C}-\mathrm{O}+\omega \mathrm{CH}$ & $2193.7(0.1)$ & - & $2194.7 v w$ & 2192.9vw & $2151.8(0.1)$ & - & - \\
\hline $2 v \mathrm{C}-\mathrm{O}$ & $2311.0(0.9)$ & - & $2349.4 v w$ & $2341.1 \mathrm{vw}$ & $2264.7(4.5)$ & $2314.7 v w$ & $2301.5 v w$ \\
\hline$v \mathrm{OD}$ & $2625.6(67.4)$ & 2631.4 & $\begin{array}{l}2618.0 s \\
2619.5 s\end{array}$ & $2631.5 \mathrm{~s}$ & $2677.4(128.6)$ & $\begin{array}{l}2668.7 \mathrm{~s} \\
2670.0 \mathrm{~m}\end{array}$ & $2685.5 \mathrm{~s}$ \\
\hline$v \mathrm{C}=\mathrm{O}+\delta \mathrm{COD}$ & $2720.2(2.5)$ & - & $2723.1 \mathrm{vw}$ & $2716.6 v w$ & $2684.7(2.1)$ & $2688.7 v w$ & $2674.4 \mathrm{vw}$ \\
\hline$v \mathrm{C}=\mathrm{O}+\omega \mathrm{CH}$ & $2776.4(0.2)$ & - & $\begin{array}{l}2732.1 v w \\
2728.7 w\end{array}$ & $2737.9 w$ & $2795.8(0.2)$ & $\begin{array}{l}2752.0 \mathrm{w} \\
2758.2 \mathrm{vw}\end{array}$ & $\begin{array}{l}2742.8 \mathrm{w} \\
2724.9 \mathrm{vw}\end{array}$ \\
\hline$v \mathrm{C}=\mathrm{O}+v \mathrm{C}-\mathrm{O}$ & 2914.8 (1.9) & - & $2940.7 w$ & $2935.5 \mathrm{~m}$ & $2929.8(2.4)$ & - & $2939 w$ \\
\hline$v \mathrm{CH}$ & $2952.8(29.7)$ & 2942 & $2961.2 \mathrm{~m}$ & $2951.9 m$ & $2861.4(47.4)$ & $\begin{array}{l}2895.3 \mathrm{~m} \\
2897.9 \mathrm{~m}\end{array}$ & $2872.7 \mathrm{~m}$ \\
\hline$\nu \mathrm{OD}+\tau \mathrm{COD}$ & $3104.4(10.0)$ & - & $\begin{array}{l}3123.3 \mathrm{vw} \\
3125.8 \mathrm{vw}\end{array}$ & $\begin{array}{l}3136.7 \mathrm{w} \\
3138.1 \mathrm{vw}\end{array}$ & $3008.1(7.6)$ & $3050.6 v w$ & $3059.2 \mathrm{vw}$ \\
\hline$v \mathrm{C}=\mathrm{O}+\gamma \mathrm{CH}$ & $3126.5(0.4)$ & & $\begin{array}{l}3134.8 \mathrm{vw} \\
3139.5 \mathrm{vw}\end{array}$ & & $3186.9(0.1)$ & & \\
\hline$v \mathrm{OD}+\mathrm{OCO}-\mathrm{CODdef}$ & $3139.3(0.5)$ & - & $\begin{array}{l}3171.2 \mathrm{vw} \\
3173.9 \mathrm{vw}\end{array}$ & $3183.0 \mathrm{vw}$ & $3240.4(0.3)$ & - & - \\
\hline $2 v \mathrm{C}=0$ & $3483.9(4.5)$ & - & $\begin{array}{l}3512.9 \mathrm{vw} \\
3522.0 \mathrm{vw}\end{array}$ & $\begin{array}{l}3524.1 \mathrm{w} \\
3529.1 \mathrm{vw}\end{array}$ & $3553.7(4.6)$ & $\begin{array}{l}3571.1 \mathrm{vw} \\
3577.3 \mathrm{vw}\end{array}$ & $\begin{array}{l}3582.2 \mathrm{w} \\
3583.2 \mathrm{vw} \\
3598.8 \mathrm{w}\end{array}$ \\
\hline$\nu \mathrm{OD}+\omega \mathrm{CH}$ & $3628.6(0.0)$ & - & - & $3601.3 v w$ & $3647.4(0.0)$ & - & $3629.4 \mathrm{vw}$ \\
\hline$v \mathrm{OD}+v \mathrm{C}-\mathrm{O}$ & $3754.7(0.0)$ & - & $3736.1 \mathrm{vw}$ & $3728.7 v w$ & $3760.4(3.9)$ & $3741.5 \mathrm{vw}$ & $3740.2 \mathrm{vw}$ \\
\hline$v \mathrm{CH}+v \mathrm{C}-\mathrm{O}$ & $4114.4(1.3)$ & 4125 & $4140.1 \mathrm{vw}$ & $4123.8 v w$ & $4001.5(1.4)$ & $\begin{array}{l}4052.4 \mathrm{vw} \\
4058.3 \mathrm{vw}\end{array}$ & $4025.9 v w$ \\
\hline$v \mathrm{OD}+v \mathrm{C}=\mathrm{O}$ & $4345.8(0.5)$ & 4404 & $4382.0 \mathrm{vw}$ & $4399.5 v w$ & $4418.2(0.3)$ & - & \\
\hline$v \mathrm{CH}+v \mathrm{C}=0$ & $4704.3(1.8)$ & 4719 & $\begin{array}{l}4720.7 \mathrm{vw} \\
4723.8 \mathrm{vw}\end{array}$ & $4714.2 \mathrm{vw}$ & $4653.6(2.1)$ & $\begin{array}{l}4687.9 \mathrm{vw} \\
4707.9 \mathrm{vw}\end{array}$ & $\begin{array}{l}4666.7 \mathrm{vw} \\
4686.8 \mathrm{vw}\end{array}$ \\
\hline $2 v \mathrm{OD}$ & $5163.6(1.1)$ & 5181 & $\begin{array}{l}5146.3 v w \\
5149.7 w \\
5152.9 v w\end{array}$ & $5174.5 \mathrm{vw}$ & $5284.7(1.1)$ & $\begin{array}{l}5249.5 \mathrm{w} \\
5252.4 \mathrm{vw} \\
5253.7 \mathrm{vw}\end{array}$ & $5280.4 \mathrm{vw}$ \\
\hline $2 v \mathrm{CH}$ & $5791.3(0.5)$ & - & $5801.7 \mathrm{vw}$ & $5769.3 \mathrm{vw}$ & $5690.9(0.5)$ & $\begin{array}{l}5592.9 v w \\
5594.4 v w\end{array}$ & $5548.6 v w$ \\
\hline
\end{tabular}

a From Refs. [7,11,26,27,29].

b Components of Fermi resonance.

stretching region are presented. The band at $2631.5 \mathrm{~cm}^{-1}$ is the OD stretching mode ( $v \mathrm{OD}$ ) of trans-HCOOD in a neon matrix. It shows good agreement with the anharmonic calculations yielding $2625.6 \mathrm{~cm}^{-1}$. For cis-HCOOD, this mode shifts to $2685.5 \mathrm{~cm}^{-1}$ (computationally to $2677.4 \mathrm{~cm}^{-1}$ ). In an argon matrix, the transand cis-HCOOD $v$ OD absorptions are at 2618.0 and $2668.7 \mathrm{~cm}^{-1}$, showing a typical matrix shift from the neon matrix values.

The CC-VSCF calculations reproduce well the experimental frequencies for most of the fundamental modes. The calculated intensities of HCOOD match the experimental values (see Fig. 3). Similarly good agreement between the anharmonic calculations and the experimental spectra was reported for HONO [28]. The high-frequency $\mathrm{OD}$ and $\mathrm{CH}$ stretching modes for the trans conformer, where anharmonicity is significant, are obtained with the $0.3 \%$ inaccuracy compared to the gas-phase data. For the torsional mode the anharmonic calculations and the experimental frequencies from the gas-phase experiments agree better for the deuterated molecule than for that of $\mathrm{HCOOH}(\sim 2 \%$ error for transHCOOD, $\sim 7 \%$ for trans-HCOOH). This is explained by the fact that the vibrational amplitude is smaller for HCOOD and the limitation of large-amplitude vibrational mode description by the CC-VSCF method becomes less important.

Among other fundamental modes, the largest difference between the calculated and experimental neon matrix values is ob- 


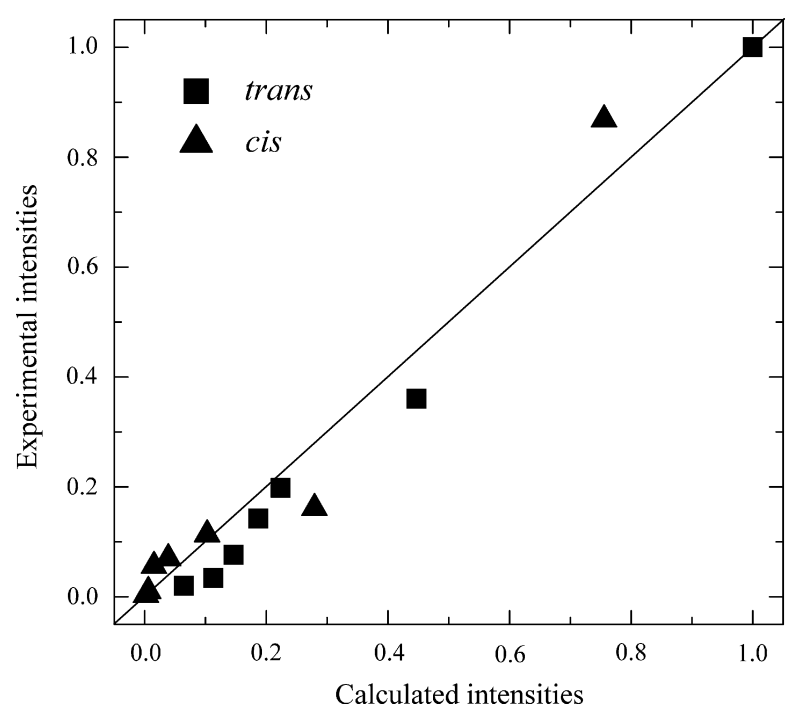

Fig. 3. Relative calculated and experimental intensities for the fundamental modes of HCOOD. The intensities are normalized by the $v \mathrm{C}=0$ intensity of trans-HCOOD. The experimental values are obtained in a neon matrix. The straight line shows 1:1 agreement with the experiment.

served for the $\mathrm{C}-\mathrm{O}$ stretching and $\mathrm{CH}$-wagging vibrations of the cis conformer $\left(\sim 20 \mathrm{~cm}^{-1}, \sim 2 \%\right)$. For the $v \mathrm{C}-\mathrm{O}$ vibration, this discrepancy possibly originates from the fact that the CC-VSCF method accounts only for pairwise couplings and the multiple interactions are neglected [19-21]. The $v \mathrm{C}-\mathrm{O}$ vibration is a mixed mode and the contribution of the OCO-COD deformational motion is large [8]. The reason for the difference between the calculated and experimental frequencies of the $\mathrm{CH}$-wagging mode remains an open question because this vibrational mode is well-isolated [8].

The assignment of vibrational transitions in the $v \mathrm{C}=0$ region is less certain due to Fermi resonances. An accurate analysis of the $v \mathrm{C}=\mathrm{O}$ vibration of trans-HCOOD in the gas phase yields that the strongest perturbation for the $v \mathrm{C}=\mathrm{O}$ vibrational state arises from the nearest $\mathrm{OCO}-\mathrm{CODdef}+v \mathrm{C}-\mathrm{O}$ combination. The energy difference between these levels is about $40 \mathrm{~cm}^{-1}$ [7]. Another combinational state $(v \mathrm{C}-\mathrm{O}+\tau \mathrm{COD})$ perturbs the $v \mathrm{C}=\mathrm{O}$ level in a considerably weaker extent because the energy gap between the levels is $\sim 90 \mathrm{~cm}^{-1}$. The key role of the $v \mathrm{C}-\mathrm{O}+\tau \mathrm{COD}$ state is the perturbation of the OCO-CODdef $+v \mathrm{C}-\mathrm{O}$ state [7]. In the case of cis-HCOOD, one may expect that the influence of the $v \mathrm{C}-\mathrm{O}+\tau \mathrm{COD}$ combination on the $v \mathrm{C}=\mathrm{O}$ state gets even smaller due to the increasing energy gap between the interacting levels, but the first overtone of the $\delta$ COD bending vibration (computationally at $1779.9 \mathrm{~cm}^{-1}$ ) might play an important role on the frequency and intensity of the $v \mathrm{C}=\mathrm{O}$ band as well as the OCO-CODdef $+v \mathrm{C}-\mathrm{O}$ and $\gamma \mathrm{CH}+\tau \mathrm{COD}$ combinations (computationally at 1760.7 and $1761.5 \mathrm{~cm}^{-1}$, respectively). The different "partners" of the Fermi resonance in the cis and trans molecules might be responsible for the significant different spectra of the two conformers in this region.

The $v \mathrm{C}=\mathrm{O}$ vibration of trans-HCOOD in a neon matrix has a single absorption shifted from the gas-phase value by $-2.6 \mathrm{~cm}^{-1}$ and in an argon it is a doublet due to the matrix site effect which is shifted by -6.4 and $-8.2 \mathrm{~cm}^{-1}$ from the gas-phase value. Similar doublet was observed for trans-HCOOH in an argon matrix [3]. The OCO-CODdef $+v C-O$ combination is observed $\sim 40 \mathrm{~cm}^{-1}$ below $\left(1730.0 \mathrm{~cm}^{-1}\right.$ in a Ne matrix) in agreement with the gas-phase values.

A triplet structure is observed in the $v \mathrm{C}=0$ region of cis-HCOOD in various matrices [13]. The intensity distribution is strikingly different for different matrices: the triplet intensity ratio is 1:7:6 in a neon matrix and 3:6:2 in an argon matrix. The presumably inter- acting combinations are predicted to be $\sim 1000$ smaller in intensity than the fundamental transition, so that the comparable values of the experimentally observed peaks suggest that the Fermi interaction actually takes place. The precise assignment of the triplet components remains an open question and exceeds the scope of the present work.

The computed intensities of the fundamental transitions agree very well with the experimental values (see Fig. 3). The strongest absorption is the trans $\mathrm{C}=0$ stretching vibration both computationally and experimentally. This allows us to relay to some extent on the calculated intensities, in addition to the frequency values, for assignment of overtones and combinations.

\subsection{Overtone and combination transitions}

A number of overtones and combination bands are observed and identified in the mid- and near-IR regions. The assignment of the overtones and combinations is based on the anharmonic CCVSCF calculations. The experimentally observed and calculated vibrational frequencies are collected in Table 1.

As an example, Fig. 2(b) presents the first OD stretching overtone of trans- and cis-HCOOD in argon and neon matrices. The $2 v \mathrm{OD}$ band of trans-HCOOD is observed in a neon matrix at $5174.5 \mathrm{~cm}^{-1}$ and predicted by the calculations at $5163.6 \mathrm{~cm}^{-1}$, which is in good agreement with the gas-phase value $\left(5181 \mathrm{~cm}^{-1}\right)$ [11]. For cis-HCOOD, the $2 v \mathrm{OD}$ absorption is predicted at $5284.7 \mathrm{~cm}^{-1}$ and observed at $5280.4 \mathrm{~cm}^{-1}$ in a neon matrix. The $2 v \mathrm{OD}$ bands are shifted to 5149.7 (trans) and $5249.5 \mathrm{~cm}^{-1}$ (cis) in an argon matrix.

If the $v C=0$ stretching vibration is involved in a combination transition, the resulting spectrum of the cis form might show a characteristic splitting (ca. $20 \mathrm{~cm}^{-1}$ ) due to the Fermi resonance in the fundamental region. For example, a very weak doublet at 4686.8 and $4666.7 \mathrm{~cm}^{-1}$ in a neon matrix and at 4687.9 and $4707.9 \mathrm{~cm}^{-1}$ in an argon matrix is assigned to the $v \mathrm{CH}+v \mathrm{C}=0$ combination mode for cis-HCOOD. The trans-HCOOD absorption band at $4714.2 \mathrm{~cm}^{-1}(\mathrm{Ne})$ and $4720.7 \mathrm{~cm}^{-1}(\mathrm{Ar})$ is assigned to the $v \mathrm{CH}+v \mathrm{C}=\mathrm{O}$ combination. In the gas-phase spectrum, this combination was observed at $4719 \mathrm{~cm}^{-1}$ for trans-HCOOD [11].

In the previous work, the doublet at 2753.4 and $2759.9 \mathrm{~cm}^{-1}$ was tentatively assigned to the $v \mathrm{C}=\mathrm{O}+2 \tau \mathrm{COH}$ combination of cis$\mathrm{HCOOH}$ in an argon matrix [3]. Two bands at 2752.0 and $2758.0 \mathrm{~cm}^{-1}$ appear in the present spectra of cis-HCOOD. We reconsider the earlier assignment because the absorptions under question show negligible isotopic shifts whereas the $v \mathrm{C}=\mathrm{O}+2 \tau \mathrm{COH}$ combination should be sensitive to the isotopic substitution with a shift of $\sim 300 \mathrm{~cm}^{-1}$. We suggest that the combination transition $v \mathrm{C}=\mathrm{O}+\omega \mathrm{CH}$ gives rise to this doublet in the spectrum of cis-HCOOD in an argon matrix. The corresponding band of trans form appear $\sim 20 \mathrm{~cm}^{-1}$ lower in frequency in agreement with the calculations. The calculated values are $2795.8 \mathrm{~cm}^{-1}$ for cis- and $2776.4 \mathrm{~cm}^{-1}$ for trans-HCOOD.

A weak absorption at $2716.6 \mathrm{~cm}^{-1}(\mathrm{Ne})$ and $2723.1 \mathrm{~cm}^{-1}(\mathrm{Ar})$ probably belongs to the $v \mathrm{C}=\mathrm{O}+\delta \mathrm{COD}$ combination mode of the trans molecule (computed at $2720.2 \mathrm{~cm}^{-1}$ ). The corresponding band of the cis form is found $\sim 30 \mathrm{~cm}^{-1}$ lower in frequency in agreement with the calculations. The bands of trans-HCOOD at $2778.6 \mathrm{~cm}^{-1}(\mathrm{Ne})$ and at 2773.2 and $2782.5 \mathrm{~cm}^{-1}$ (Ar) might belong to the $v \mathrm{C}=\mathrm{O}+2 \tau \mathrm{COD}$ mode although we do not have a theoretical estimate for this frequency.

Several other absorptions also admit multiple assignments. There are two doublets of trans-HCOOD at $3123.3,3125.8 \mathrm{~cm}^{-1}$ and at $3134.8,3139.5 \mathrm{~cm}^{-1}$ in argon matrices, whose assignment is not certain. Two combination modes of trans-HCOOD are expected to absorb in this region: the $v \mathrm{OD}+\tau \mathrm{COD}$ mode (computed at $3104.4 \mathrm{~cm}^{-1}$ ) and the $v \mathrm{C}=\mathrm{O}+\gamma \mathrm{CH}$ mode (computed at $3126.5 \mathrm{~cm}^{-1}$ ). We tentatively assign two peaks at 3123.3 and $3125.8 \mathrm{~cm}^{-1}$ to the $\nu \mathrm{OD}+\tau$ COD mode 
because they are lower in frequency than the other pair which makes a better agreement with the calculations. The corresponding peaks in a neon matrix are significantly shifted to higher frequencies (3136.7 and $3138.1 \mathrm{~cm}^{-1}$ ) as it should be for this combination whereas the $\nu \mathrm{C}=\mathrm{O}+\gamma \mathrm{CH}$ mode should demonstrate only a small shift (if any) due to the opposite matrix-induced shifts of the $v \mathrm{C}=\mathrm{O}$ and $\gamma \mathrm{CH}$ fundamentals. The $v \mathrm{OD}+\tau \mathrm{COD}$ bands of the cis form is found substantially lower in frequency [3050.6 (Ar) and $\left.3059.2 \mathrm{~cm}^{-1}(\mathrm{Ne})\right]$ in agreement with calculations $\left(3008.1 \mathrm{~cm}^{-1}\right)$. The other doublet $\left(3134.8,3139.5 \mathrm{~cm}^{-1}\right)$ probably originates from the $v \mathrm{C}=\mathrm{O}+\gamma \mathrm{CH}$ combination of trans-HCOOD. The $v \mathrm{C}=\mathrm{O}+\gamma \mathrm{CH}$ band of cis-HCOOD is predicted at higher frequencies $\left(3186.9 \mathrm{~cm}^{-1}\right)$, and it is not found due to its weakness.

For trans-HCOOD, the bands at 3524.1 and $3529.1 \mathrm{~cm}^{-1}$ in a neon matrix cannot be unambiguously distinguished between the $v \mathrm{C}=\mathrm{O}$ overtone and the $v \mathrm{OD}+\delta \mathrm{COD}$ combination. We tend to assign these bands and the corresponding absorptions of cisHCOOD at 3582.2 and $3598.8 \mathrm{~cm}^{-1}$ to the $2 v \mathrm{C}=0$ mode since they show a characteristic splitting of the $v \mathrm{C}=\mathrm{O}$ fundamental region. In addition, the $v \mathrm{OD}+\delta \mathrm{COD}$ absorption of the cis form is expected at significantly lower frequencies (calculated at $3492.5 \mathrm{~cm}^{-1}$ ) and $\sim 10$ times smaller in intensity while we observe a blue shift of the cis absorptions and comparable intensities.

For very weak bands of the trans conformer at 1949.7 and $1950.6 \mathrm{~cm}^{-1}$ in argon and neon matrices two plausible assignments are suggested by the calculations: $2 \delta$ COD $\left(1938.3 \mathrm{~cm}^{-1}\right)$ and OCOCODdef $+\gamma \mathrm{CH}\left(1938.3 \mathrm{~cm}^{-1}\right)$. Nevertheless, several arguments favor the assignment to $2 \delta \mathrm{COD}$. For OCO-CODdef $+\gamma \mathrm{CH}$, the experimental coupling constants have unrealistically large positive values (ca. $+20 \mathrm{~cm}^{-1}$ ) whereas the anharmonicity constants for $2 \delta$ COD are $+4.2 \mathrm{~cm}^{-1}$ for both matrices which is more reasonable. Moreover, the computed intensity of the $2 \delta$ COD mode is higher than for the other candidate. The $2 \delta \mathrm{COD}$ band of cis-HCOOD cannot be unambiguously assigned because it is predicted in the $C=0$ stretching region and probably participates in the Fermi resonance mentioned above.

A few absorptions are observed only for one conformer. The bands at $4399.5 \mathrm{~cm}^{-1}$ in neon and $4382.0 \mathrm{~cm}^{-1}$ in argon matrices are assigned to the $v \mathrm{OD}+v \mathrm{C}=\mathrm{O}$ combination of the trans form, which is predicted by calculations at $4345.8 \mathrm{~cm}^{-1}$. The $v \mathrm{C}-\mathrm{O}+\omega \mathrm{CH}$ combination band of trans-HCOOD (calculated at $2193.7 \mathrm{~cm}^{-1}$ ) is observed at $2192.9 \mathrm{~cm}^{-1}$ in neon and at $2194.7 \mathrm{~cm}^{-1}$ in argon matrices. These modes are not observed for cis-HCOOD supposedly due to their weakness.

The computed CC-VSCF frequencies for the bands, which were not detected in the spectra, are collected in Table 3. Most of these modes are computationally very weak $(<0.5 \mathrm{~km} / \mathrm{mol})$. The torsional mode for cis-HCOOD most probably lies below our measurement limit of $450 \mathrm{~cm}^{-1}$. The expected positions of some combination bands or overtones are close to intense fundamentals, which complicate their detection. For example, the 20CO-CODdef band for transHCOOD should be at $\sim 1110 \mathrm{~cm}^{-1}$, which coincides with the $v \mathrm{C}-\mathrm{O}$ stretching region.

There are small discrepancies with the previously published data (see Table 3 in Ref. [3]). We suppose that the observed frequency deviations of $1-2 \mathrm{~cm}^{-1}$ are due to relatively high inaccuracy for the high-frequency region and differences in sample preparations. A relatively poor signal-to-noise ratio impeded to find two peaks at 4142.6 and $4380.2 \mathrm{~cm}^{-1}$ reported previously for the $v \mathrm{CH}+v \mathrm{C}-\mathrm{O}$ and $v \mathrm{OD}+v \mathrm{C}=0$ modes in an argon matrix [3].

\subsection{Anharmonicity and coupling constants}

Table 2 shows coupling and anharmonicity constants of for trans- and cis-HCOOD which are calculated by the formulas [15]:

$x_{i j}=v_{i+j}-v_{i}-v_{j}$

$x_{i i}=\frac{1}{2}\left(v_{2 i}-2 v_{i}\right)$.

Here $v_{i}$ and $v_{j}$ are the fundamental frequencies, $v_{2 i}$ is the overtone frequency, $v_{i+j}$ is the combination frequency, $x_{i j}$ is the coupling constant, and $x_{i i}$ is the anharmonicity constant. The corresponding results for trans- and cis- $\mathrm{HCOOH}$ were previously reported by Maçôas et al. [3].

Table 2

Experimental and CC-VSCF calculated anharmonicity and coupling constants (in $\mathrm{cm}^{-1}$ ) for trans- and cis-HCOOD in gas phase, argon and neon matrices.

\begin{tabular}{|c|c|c|c|c|c|c|c|}
\hline & \multicolumn{4}{|c|}{ trans-HCOOD } & \multicolumn{3}{|c|}{ cis-HCOOD } \\
\hline & $\mathrm{Ar}$ & $\mathrm{Ne}$ & $\mathrm{Gas}^{\mathrm{a}}$ & Calc & $\mathrm{Ar}$ & $\mathrm{Ne}$ & Calc \\
\hline Combinations & \multicolumn{7}{|c|}{ Coupling constants $\left(x_{i j}\right)$} \\
\hline OCO-CODdef. + vOD & -5.5 & -6.4 & & -42.0 & & & -58.5 \\
\hline $\mathrm{OCO}-\mathrm{CODdef} .+v \mathrm{C}-\mathrm{O}$ & -5.7 & -4.8 & -5.2 & -3.8 & & \multirow{3}{*}{-2.0} & -1.7 \\
\hline$\delta \mathrm{COD}+\mathrm{OCO}-\mathrm{CODdef}$. & & -2.7 & & +5.1 & \multirow[t]{2}{*}{-0.9} & & +5.5 \\
\hline$\delta \mathrm{COD}+\omega \mathrm{CH}$ & +1.4 & +0.2 & & -1.1 & & & 0.0 \\
\hline$\delta \mathrm{COD}+v \mathrm{C}-\mathrm{O}$ & -8.2 & -8.2 & & -6.8 & \multirow[t]{2}{*}{-9.4} & \multirow[t]{2}{*}{-10.6} & -8.7 \\
\hline$\delta \mathrm{COD}+\tau \mathrm{COD}$ & -47.6 & -45.0 & & -29.2 & & & -51.5 \\
\hline$\delta \mathrm{COD}+v \mathrm{C}=0$ & -21.2 & -19.0 & & -3.8 & \multirow[t]{2}{*}{-21.1} & \multirow[t]{2}{*}{-31.3} & -2.7 \\
\hline$v \mathrm{C}-\mathrm{O}+\omega \mathrm{CH}$ & -23.4 & -21.3 & & -3.2 & & & -3.5 \\
\hline$v \mathrm{C}-\mathrm{O}+v \mathrm{OD}$ & -65.1 & -79.7 & & -34.6 & -91.2 & -104.3 & -57.9 \\
\hline$v \mathrm{C}-\mathrm{O}+v \mathrm{CH}$ & -2.8 & -5.0 & -4.9 & -2.1 & \multirow[t]{8}{*}{-9.5} & \multirow[t]{3}{*}{-5.8} & -0.8 \\
\hline$v \mathrm{C}=\mathrm{O}+v \mathrm{C}-\mathrm{O}$ & -6.6 & -12.4 & & -0.2 & & & -0.6 \\
\hline$v \mathrm{C}=\mathrm{O}+\omega \mathrm{CH}$ & -26.7 & -29.7 & & -8.1 & & & -8.1 \\
\hline$v \mathrm{C}=\mathrm{O}+v \mathrm{OD}$ & -1.6 & -3.0 & -1.0 & -31.1 & & & -48.7 \\
\hline$v \mathrm{C}=\mathrm{O}+v \mathrm{CH}$ & -6.1 & -8.7 & -13.0 & +0.2 & & & -2.7 \\
\hline$\nu \mathrm{C}=\mathrm{O}+\gamma \mathrm{CH}$ & -3.5 & & & -5.9 & & & -6.2 \\
\hline$v \mathrm{OD}+\tau \mathrm{COD}$ & \multirow[t]{2}{*}{-1.4} & -1.7 & & -18.7 & & \multirow{3}{*}{-95.4} & -30.7 \\
\hline$v \mathrm{OD}+\omega \mathrm{CH}$ & & -67.5 & & -30.2 & & & -44.4 \\
\hline Overtones & \multicolumn{4}{|c|}{ Anharmonicity constants $\left(x_{i i}\right)$} & & & \\
\hline $2 v \mathrm{CH}$ & -60.4 & -67.3 & & -57.2 & -98.9 & -98.4 & -15.9 \\
\hline $2 v \mathrm{OD}$ & -44.9 & -44.3 & -40.9 & -43.8 & -43.9 & -45.3 & -35.1 \\
\hline $2 v \mathrm{C}=\mathrm{O}$ & -9.35 & -9.35 & & -9.35 & -13.75 & $-7.3^{\mathrm{b}}$ & $-12.6^{\mathrm{b}}$ \\
\hline $2 v \mathrm{C}-\mathrm{O}$ & -7.0 & -6.4 & & -8.2 & -5.15 & -8.1 & -8.5 \\
\hline $2 \delta \mathrm{COD}$ & +4.2 & +4.2 & & -3.7 & & & -7.9 \\
\hline $2 \tau \mathrm{COD}$ & -1.1 & -2.1 & -1.6 & -17.0 & & & -17.3 \\
\hline
\end{tabular}

a From Refs. [7,11,26,27,29].

b Values for the most intensive component of $v \mathrm{C}=\mathrm{O}$ band $\left(1798.9\right.$ in $\mathrm{Ne}$ and $1799.3 \mathrm{~cm}^{-1}$ in $\left.\mathrm{Ar}\right)$. 
Table 3

CC-VSCF vibrational frequencies $\left(\mathrm{cm}^{-1}\right)$ of non-observed absorptions for the transand cis-HCOOD. Calculated intensities in $\mathrm{km} / \mathrm{mol}$ are given in parentheses.

\begin{tabular}{llr}
\hline Assignment & trans-HCOOD & \multicolumn{1}{c}{ cis-HCOOD } \\
\hline OCO-CODdef $+\tau$ COD & $1038.7(0.2)$ & $950.0(0.0)$ \\
2 OCO-CODdef & $1107.0(0.1)$ & $1231.4(0.0)$ \\
$\omega \mathrm{CH}+\tau \mathrm{COD}$ & $1533.2(0.1)$ & $1378.9(0.2)$ \\
OCO-CODdef $+\omega \mathrm{CH}$ & $1588.4(0.0)$ & $1634.8(0.0)$ \\
$v \mathrm{C}-\mathrm{O}+\tau \mathrm{COD}$ & $1653.7(0.0)$ & $1479.7(0.2)$ \\
$\gamma \mathrm{CH}+\tau \mathrm{COD}$ & $1877.2(0.0)$ & $1761.5(0.0)$ \\
$\mathrm{OCO}-\mathrm{CODdef}+\gamma \mathrm{CH}$ & $1938.3(0.0)$ & $2026.9(0.0)$ \\
$\nu \mathrm{C}=\mathrm{O}+\tau \mathrm{COD}$ & $2245.6(0.1)$ & $2145.6(0.0)$ \\
$\gamma \mathrm{CH}+\delta \mathrm{COD}$ & $2354.1(0.0)$ & $2303.2(0.1)$ \\
$v \mathrm{C}-\mathrm{O}+\gamma \mathrm{CH}$ & $2542.8(0.0)$ & $2540.8(0.1)$ \\
$2 \gamma \mathrm{CH}$ & $2760.9(0.7)$ & $2980.1(0.9)$ \\
$v \mathrm{CH}+\tau \mathrm{COD}$ & $3447.4(0.0)$ & $3220.0(0.1)$ \\
$\nu \mathrm{CH}+\mathrm{OCO}-\mathrm{CODdef}$ & $3509.6(0.1)$ & $3481.8(0.1)$ \\
$v \mathrm{OD}+\delta \mathrm{COD}$ & $3535.4(2.0)$ & $3492.5(0.3)$ \\
$v \mathrm{CH}+\omega \mathrm{CH}$ & $3923.4(0.0)$ & $3816.5(0.1)$ \\
$v \mathrm{CH}+\delta \mathrm{COD}$ & $3926.9(0.0)$ & $3760.7(0.1)$ \\
$v \mathrm{OD}+\gamma \mathrm{CH}$ & $3975.5(0.1)$ & $4035.1(0.0)$ \\
$v \mathrm{CH}+\gamma \mathrm{CH}$ & $4275.8(0.4)$ & $4208.0(0.1)$ \\
\hline \hline
\end{tabular}

It is seen from Table 2 that the CC-VSCF calculations reproduce very well the anharmonic properties of the overtone transitions (with an exception of the $2 \tau$ COD mode) although they are somewhat less precise for the cis form. The absolute value of the anharmonicity constant for the $2 v \mathrm{OD}$ band is about two times smaller than for $2 v \mathrm{OH}$ [3], and the agreement with the gas-phase data is good.

The calculated coupling constants show poorer agreement with the experimental results. For most of the bands $(\delta \mathrm{COD}+v \mathrm{C}=\mathrm{O}$, $v \mathrm{C}-\mathrm{O}+v \mathrm{OD}$, etc.) the experimental coupling constants for both matrix hosts and the gas phase (when available) are larger than the predicted value, which demonstrate that the calculations underestimate the anharmonicity effect for HCOOD. The calculated coupling constants appear overestimated only for the OCO-CODdef. $+v \mathrm{OD}$ and $v \mathrm{C}=\mathrm{O}+v \mathrm{OD}$ combination modes. The opposite trend was observed for $\mathrm{HCOOH}$, where most of the coupling constants were overestimated [3].

The COD bending mode has unusual properties. The $2 \delta \mathrm{COD}$ overtone has positive experimental anharmonicity constant $\left(+4.2 \mathrm{~cm}^{-1}\right.$ for both matrices) whereas the calculations predict a negative value of $-3.7 \mathrm{~cm}^{-1}$. The $\delta \mathrm{COD}+\omega \mathrm{CH}$ combination band also has positive experimental coupling constants, and two combinations $(\delta \mathrm{COD}+\mathrm{OCO}-\mathrm{CODdef}$ and $\nu \mathrm{C}=\mathrm{O}+\gamma \mathrm{CH})$ demonstrate the positive values of calculated coupling constants. We assume that the Fermi resonance of $\delta$ COD and the overtone of the $\tau$ COD mode in trans-HCOOD [27] might be at least partly responsible for the peculiarities of the $\delta$ COD mode.

Except for the $v \mathrm{C}=\mathrm{O}+v \mathrm{CH}$ vibration, no significant differences between experimental anharmonicity and coupling constants in matrices and the gas phase are observed which means that the geometries and the electronic properties of the molecules are not significantly perturbed by matrix hosts.

\section{Conclusions}

The vibrational spectra of trans- and cis-HCOOD in neon and argon matrices are studied in the $7900-450 \mathrm{~cm}^{-1}$ region. Most of the relatively strong combination and overtone modes predicted by the CC-VSCF method are detected in matrices. The fundamental frequencies and intensities are well reproduced by the CC-VSCF calculations. The calculated combination and overtones frequencies show sometimes a considerable shift from the experimental values up to $\sim 50 \mathrm{~cm}^{-1}$, nevertheless, the relative error does not exceed $\sim 3 \%$. The near- and mid-IR data for cis-HCOOD in a neon matrix is reported here for the first time.

\section{Acknowledgments}

This work was supported by the Academy of Finland through the Finnish Center of Excellence in Computational Molecular Science, the Research Foundation of the University of Helsinki, CSC - Center for Scientific Computing Ltd. (Espoo, Finland) and the Finnish Centre for International Mobility (CIMO). A.D. acknowledges a postdoctoral grant from the Faculty of Science, University of Helsinki (Project No. 7500101).

\section{References}

[1] W.H. Hocking, Z. Naturforsch. 31A (1976) 1113-1121.

[2] M. Pettersson, J. Lundell, L. Khriachtchev, M. Räsänen, J. Am. Chem. Soc. 119 (1997) 11715-11716.

[3] E.M.S. Maçôas, J. Lundell, M. Pettersson, L. Khriachtchev, R. Fausto, M. Räsänen, J. Mol. Spectrosc. 219 (2003) 70-80.

[4] L. Khriachtchev, J. Mol. Struct. 880 (2008) 14-22.

[5] M. Freytes, D. Hurtmans, S. Kassi, J. Lievin, J. Vander Auwera, A. Campargue, M. Herman, Chem. Phys. 283 (2002) 47-61.

[6] O. Baskakov, I. Markov, E. Alekseev, R. Motiyenko, J. Lohilahti, V.-M. Horneman, B. Winnewisser, I. Medvedev, F. De Lucia, J. Mol. Struct. 795 (2006) 54-77.

[7] O. Baskakov, J. Mol. Spectrosc. 213 (2002) 1-7.

[8] R.L. Redington, J. Mol. Spectrosc. 65 (1977) 171-189.

[9] D.O. Henderson, Doctoral Thesis, Texas Technical University, 1987.

[10] O. Baskakov, V.-M. Horneman, J. Lohilahti, S. Alanko, J. Mol. Struct. 795 (2006) 49-53.

[11] V. Lattanzi, A. Walters, B. Drouin, J. Pearson, Astron. Astrophys. Suppl. Ser. 176 (2008) 536-542.

[12] W.H. Hocking, Z. Naturforsch. 33A (1978) 610-618.

[13] A. Domanskaya, K. Marushkevich, L. Khriachtchev, M. Räsänen, J. Chem. Phys. 130 (2009) 154509.

[14] J. Demaison, M. Herman, J. Liévin, J. Chem. Phys. 126 (2007) 164305.

[15] G. Herzberg, Molecular Spectra and Molecular Structure. Infrared and Raman Spectra of Polyatomic Molecules, Krieger Publishing Company, Malabar, FL, 1991.

[16] J. Lundell, M. Räsänen, Z. Latajka, Chem. Phys. 189 (1994) 245-260.

[17] J. Lundell, Chem. Phys. Lett. 266 (1997) 1-6.

[18] M.W. Schmidt, K.K. Baldridge, J.A. Boatz, S.T. Elbert, M.S. Gordon, J.H. Jensen, S. Koseki, N. Matsunaga, K.A. Nguyen, S.J. Su, T.L. Windus, M. Dupuis, J.A. Montgomery, J. Comput. Chem. 14 (1993) 1347-1363.

[19] G.M. Chaban, J.-O. Jung, R.B. Gerber, J. Chem. Phys. 111 (1999) 1823.

[20] J.-O. Jung, R.B. Gerber, J. Chem. Phys. 105 (1996) 10332.

[21] J.-O. Jung, R.B. Gerber, J. Chem. Phys. 105 (1996) 10682.

[22] J. Lundell, M. Pettersson, L. Khriachtchev, M. Räsänen, G.M. Chaban, R.B. Gerber, Chem. Phys. Lett. 322 (2000) 389-394.

[23] G.M. Chaban, J.-O. Jung, R.B. Gerber, J. Phys. Chem. A 104 (2000) $2772-$ 2779 .

[24] E.M.S. Maçôas, L. Khriachtchev, M. Pettersson, R. Fausto, M. Räsänen, Phys. Chem. Chem. Phys. 7 (2005) 743-749.

[25] M. Pettersson, E.M.S. Maçôas, L. Khriachtchev, J. Lundell, R. Fausto, M. Räsänen, J. Chem. Phys. 117 (2002) 9095-9098.

[26] J.E. Bertie, K.H. Michaelian, H.H. Eysel, D.J. Hager, Chem. Phys. 85 (1986) 47794789 .

[27] T. Tan, K. Goh, P. Ong, H. Teo, J. Mol. Spectrosc. 198 (1999) 110-114.

[28] L. Khriachtchev, J. Lundell, E. Isoniemi, M. Räsänen, J. Chem. Phys. 113 (2000) 4265.

[29] I.C. Hisatsune, J. Heicklen, Can. J. Specrosc. 18 (1973) 135-142. 